\title{
Reactions of salicylaldehyde and enolates or their equivalents: versatile synthetic routes to chromane derivatives
}

\author{
Ishmael B. Masesane ${ }^{*}$ and Zelalem Yibralign Desta
}

\section{Review}

Address:

Department of Chemistry, University of Botswana, Private Bag 00704,

Gaborone, Botswana

\section{Email:}

Ishmael B. Masesane* - masesane@mopipi.ub.bw

* Corresponding author

Keywords:

acetophenone; chromane; enolates; malononitrile; Michael addition;

salicylaldehyde
Beilstein J. Org. Chem. 2012, 8, 2166-2175.

doi:10.3762/bjoc. 8.244

Received: 25 September 2012

Accepted: 23 November 2012

Published: 12 December 2012

Associate Editor: T. P. Yoon

(C) 2012 Masesane and Desta; licensee Beilstein-Institut.

License and terms: see end of document.

\begin{abstract} nitroalkanes, malononitrile and $\alpha, \beta$-unsaturated compounds.

\section{Introduction}

The chromane skeleton is found in a myriad of medicinally important compounds that have a broad range of biological activities [1-7]. Consequently, the synthesis of chromane derivatives has attracted the attention of synthetic chemists over the years [1-17]. Among the reported methodologies for the synthesis of chromane derivatives, the reaction of salicylaldehyde and enolates or their equivalents has gained a prominent position. The key features of the synthesis of chromane derivatives by the reaction of salicylaldehyde and enolates are summarized retrosynthetically in Scheme 1.
\end{abstract}

The reported methodologies for the synthesis of chromane derivatives through the reaction of salicylaldehyde and enolates are discussed. The enolates and their equivalents involved in the reactions discussed in this article were derived from ketones,

This review will summarize the reported methods for the syntheses of chromane derivatives from the reaction of salicylaldehyde and enolates or their equivalents. For the purposes of this review, chromane derivatives will include flavans, flavones, chromenes and chromones. The synthetic methods in the literature will be compared and contrasted in terms of their generality, selectivity and percentage yields.

\section{Review}

Chromane derivatives from the reaction of salicylaldehyde with enolates derived from ketones

The reaction of salicylaldehyde (5) and enolates derived from acetophenone (7) has been employed by a number of chemists in the synthesis of flavans and flavones. Flavans are chromane derivatives with a $\mathrm{C}-2$ phenyl substituent while flavones are chromane derivatives with a carbonyl functional group at $\mathrm{C}-4$, a carbon-carbon double bond between $\mathrm{C}-2$ and C-3, and a C-2 


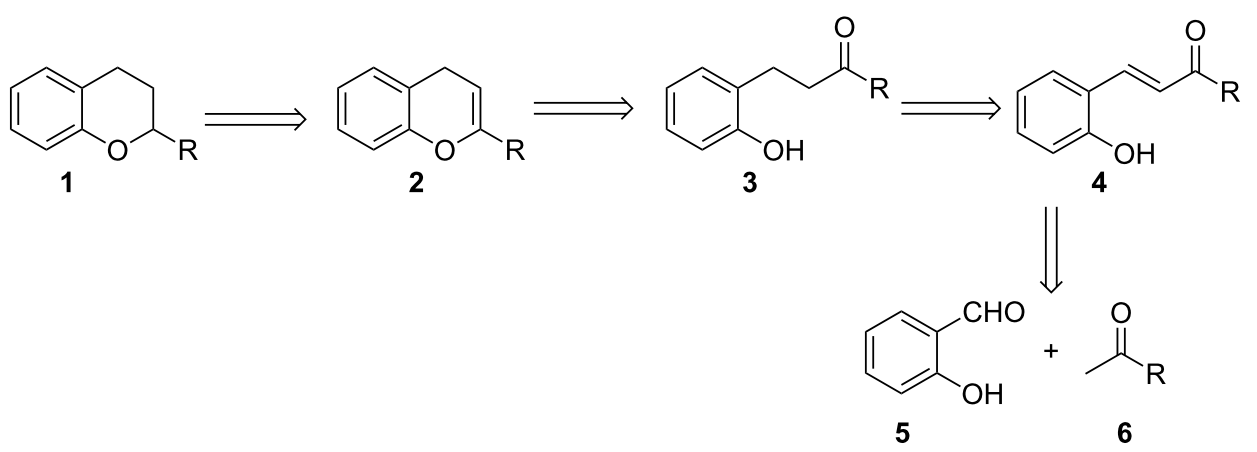

Scheme 1: Retrosynthetic analysis of chromane 1.

phenyl substituent. The synthesis of flavans and flavones generally involves treatment of acetophenone (7) with a base to give enolate 8, which undergoes a Knoevenagel condensation with salicylaldehyde (5) to yield a chalcone $\mathbf{9}$. These chalcone derivatives are then cyclized by using various methodologies to give flavan $\mathbf{1 0}$ or flavone $\mathbf{1 1}$ (Scheme 2).
Xue and co-workers have utilized the reaction of salicylaldehyde $\mathbf{1 2}$ and acetophenone $\mathbf{1 3}$ in the racemic synthesis of the naturally occurring flavan 16 (Scheme 3) [18]. To begin, a solution of 12 and $\mathbf{1 3}$ in $\mathrm{CH}_{3} \mathrm{OH}$ was stirred in the presence of $\mathrm{KOH}$ at room temperature to give chalcone 14. To set the stage for the cyclisation reaction, the trans carbon-carbon double bond<smiles>CC(=O)c1ccccc1</smiles>

7<smiles>O=C(O)c1ccccc1</smiles>

8<smiles>O=Cc1ccccc1O</smiles><smiles>O=C(/C=C/c1ccccc1O)c1ccccc1</smiles>

9<smiles>O=c1cc(-c2ccccc2)oc2ccccc12</smiles>

11

Scheme 2: General reaction of salicylaldehyde (5) and acetophenone (7) in the synthesis of flavan 10 and flavone 11.<smiles>[R]Oc1ccc(C=O)c([R])c1</smiles>

12

$\mathrm{R}=\mathrm{MOM}=\mathrm{CH}_{3} \mathrm{OCH}_{2}$<smiles>COc1ccc(C2CCc3ccc(O)cc3O2)cc1O</smiles>

16<smiles>[R]Oc1cc(C(C)=O)ccc1OC</smiles>

13<smiles>[R]Oc1ccc(/C=C/C(=O)c2ccc(OC)c(O[R])c2)c([R])c1</smiles>

$\mathrm{H}_{2} / \mathrm{Pd}(5 \%)$

$\mathrm{EtOH}, 99 \%$

Scheme 3: Synthesis of flavan 16 by Xue and co-workers. 
<smiles>O=Cc1ccccc1O</smiles>

5<smiles>CC(C)c1ccc(O)c(C=CC(=O)C2=[R]=CC=CC2C(=O)O)c1</smiles>

$9(\mathrm{R}=\mathrm{H}, 85 \%)$

9a $(\mathrm{R}=0-\mathrm{OMe}, 83 \%)$

$9 \mathrm{~b}(\mathrm{R}=m-\mathrm{OMe}, 66 \%)$

9c $(\mathrm{R}=p-\mathrm{OMe}, 78 \%)$<smiles>[R]c1cccc(C(O)CCc2cc(C)ccc2O)c1</smiles>

$17(\mathrm{R}=\mathrm{H}, 88 \%)$

$17 \mathrm{a}(\mathrm{R}=0-\mathrm{OMe}, 81 \%)$

$17 \mathrm{~b}(\mathrm{R}=m-\mathrm{OMe}, 62 \%$

$17 \mathrm{c}(\mathrm{R}=p-\mathrm{OMe}, 90 \%)$<smiles>[R][R]1cccc([C@@H]2C[C@H](C(=O)O)c3ccccc3O2)c1</smiles>

$10(\mathrm{R}=\mathrm{H}, 71 \%)$

$10 \mathrm{a}(\mathrm{R}=0-\mathrm{OMe}, 83 \%)$

$10 \mathrm{~b}(\mathrm{R}=m-\mathrm{OMe}, 62 \%)$

10c $(\mathrm{R}=0-\mathrm{OMe}, 87 \%)$

Scheme 4: Synthesis of flavans of type 10 by Mazimba and co-workers.

must either be isomerized to the cis form or completely reduced. In this case, chalcone $\mathbf{1 4}$ was treated with $\mathrm{H}_{2}$ in the presence of a catalytic amount of Pd to give intermediate $\mathbf{1 5}$ in $99 \%$ yield. It is instructive to draw attention to the fact that both the carbon-carbon and carbon-oxygen double bonds of $\mathbf{1 4}$ were reduced by $\mathrm{H}_{2} / \mathrm{Pd}$, a reagent usually used for the reduction of carbon-carbon double bonds. To complete the synthesis, Lewis acid mediated cyclization of intermediate $\mathbf{1 5}$ and acidic cleavage of the MOM protected hydroxy group delivered the desired flavan $\mathbf{1 6}$ in good yield.

On the basis of the above precedent by Xue and co-workers, our group accomplished the synthesis of an array of flavans of type 10 [19]. The synthesis begins with a Knoevenagel reaction of salicylaldehyde (5) and acetophenone derivatives 7 to give the corresponding chalcones of type $\mathbf{9}$ in $66-85 \%$ yields. Contrary to Xue's reduction method where $\mathrm{H}_{2} / \mathrm{Pd}$ was used, we used $\mathrm{NaBH}_{4}$ in the reduction of both the carbon-carbon and carbon-oxygen double bonds of chalcone derivatives 9 to give the corresponding alcohols 17. It is noteworthy that the carbon-carbon double bond was also reduced by $\mathrm{NaBH}_{4}$, a reagent usually used for the reduction of carbonyl groups. Cyclization was achieved by heating intermediates $\mathbf{1 7}$ under reflux in acetic acid to give the corresponding flavans of type 10 in $62-87 \%$ yields (Scheme 4 ).

Recently, Sashidhara and co-workers achieved the synthesis of flavone 11 relying on the reaction of salicylaldehyde (5) and an enolate derived from acetophenone (7, Scheme 5) [20]. To begin, chalcone 9 was prepared in $85 \%$ yield by the Knoevenagel reaction of salicylaldehyde (5) and acetophenone (7) in the presence of $\mathrm{KOH}(\mathrm{aq})$ in ethanol as reported by Mazimba and co-workers. Chalcone 9 was then oxidatively cyclized in the presence of iodine and in a solvent-free environment to give flavone (11) in 72\% yield. Methyl-, methoxy- and chlorosubstituted acetophenones were also well tolerated in the reaction to give the corresponding flavones in comparable yields.

It is conceivable that enolates derived from other ketones instead of acetophenone could be reacted with salicylaldehyde to give chromane derivatives. To this end, Yu Ling and co-workers reported the efficient synthesis of chromane deriva-<smiles>CC(=O)c1ccccc1</smiles> 
tive 19 through the reaction of salicylaldehyde (5) with dimedone (18) in the presence of a catalytic amount of $\mathrm{KF} / \mathrm{Al}_{2} \mathrm{O}_{3}$ (Scheme 6) [21]. The reaction is thought to proceed through a Knoevenagel condensation, a Michael addition and an intramolecular cyclization. The reaction was repeated with chloro-, bromo-, dichloro-, dibromo-, methyl- and nitro-substituted salicylaldehydes. The nitro- and 3,5-dibromo-substituted salicylaldehydes reacted with 18 to give the lowest yields of $60-70 \%$ while the other substituted salicylaldehydes reacted to give corresponding chromane derivatives in yields comparable to those achieved when $\mathbf{5}$ was used.<smiles>CC1(CC(=O)OCC(=O)O)CC(=O)CC(=O)C1</smiles>

5

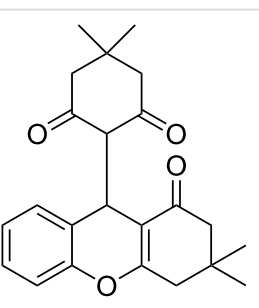

19
Scheme 6: Synthesis of chromane derivative 19 by Yu-Ling and co-workers.

\section{Chromane derivatives from the reactions of salicylaldehyde and enolate equivalents derived from malononitrile and its derivatives}

The one-pot reaction of salicylaldehyde and malononitrile has proved to be an efficient method for the synthesis of 2-iminochromene derivatives. In general such synthetic procedures involve a Knoevenagel condensation followed by intramolecular cyclization. In a detailed study directed towards understanding the pathway of the reaction of salicylaldehyde (5) and malononitrile (20), Costa and co-workers reported the effi- cient synthesis of 2-iminochromene 21 in $90 \%$ yield [22]. This was achieved when salicylaldehyde (5) was reacted with 1 equivalent of malononitrile in the presence of $\mathrm{Na}_{2} \mathrm{CO}_{3}$ and $\mathrm{H}_{2} \mathrm{O}$ as the solvent (Scheme 7). A comparable yield was obtained when $\mathrm{NaHCO}_{3}$ was used as the base instead of $\mathrm{Na}_{2} \mathrm{CO}_{3}$. The use of 3-methoxy-, 3-hydroxy-, 5-bromo-, 4- $N, N$-diethylaminoand 5-bromo-3-methoxy-substituted salicylaldehydes gave corresponding 2-iminochromene derivatives in $86-100 \%$ yields, while the lowest yield of $62 \%$ was achieved when 3,4-dihydroxysalicylaldehyde was used.

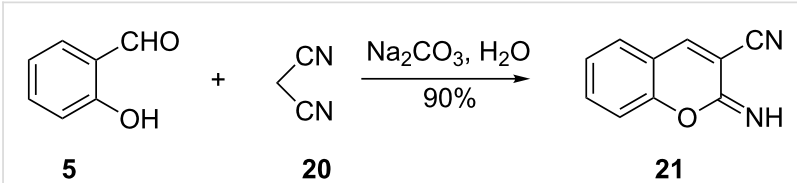

Scheme 7: Synthesis of 2-iminochromene 21 by Costa and co-workers.

Further studies by Costa and co-workers revealed that the reaction of salicyldehyde (5) with 2 equivalents of malonitrile (20) in the presence of $\mathrm{NaHCO}_{3}$ afforded 2-aminochromene $\mathbf{2 2}$ in 91\% yield (Scheme 8) [22]. This product is thought to be the result of a Michael addition of the extra malononitrile to product 21 .

In addition to inorganic bases such as $\mathrm{Na}_{2} \mathrm{CO}_{3}$ and $\mathrm{NaHCO}_{3}$, the use of amines in catalytic and quantitative amounts in the synthesis of chromane derivatives by the reaction of salicylaldehyde (5) and malononitrile (20) has been reported. Costa and co-workers used $\mathrm{Et}_{3} \mathrm{~N}$ in the reaction of salicylaldehyde and 2 equivalents of malononitrile (20) in $\mathrm{CH}_{3} \mathrm{OH}$ to afford 2-aminochromene $\mathbf{2 4}$ in 94\% yield (Scheme 9) [22].<smiles>O=Cc1ccccc1O</smiles>
5<smiles>N#CCC#N</smiles>

20<smiles>N#Cc1cc2ccccc2oc1=N</smiles>

21

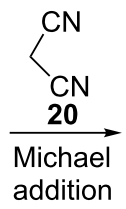
addition<smiles>N#CC1=C(N)Oc2ccccc2C1C(C#N)C#N</smiles>

22

Scheme 8: Synthesis of 2-aminochromene 22 by Costa and co-workers.<smiles>COc1cccc(C=O)c1O</smiles>

23<smiles>[14CH2]CC#N</smiles>

20<smiles>COc1cccc2c1OC(N)=C(C#N)C2C(C#N)C#N</smiles>

24

Scheme 9: Costa and co-workers used $\mathrm{Et}_{3} \mathrm{~N}$ in the synthesis of 2-aminochromene 24. 

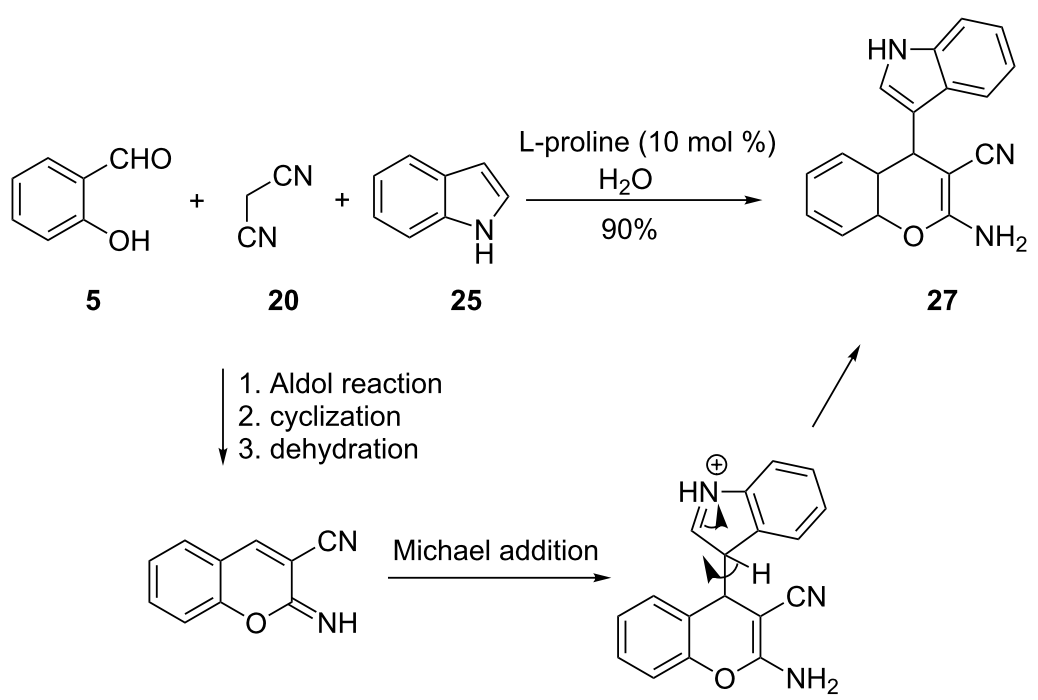

21

26

Scheme 10: Synthesis of 2-aminochromene 27 by Shanthi and co-workers.

In 2009, Shanthi and co-workers reported the use of the amino acid L-proline as a catalyst in a three component reaction of salicylaldehyde, malononitrile and indole for the synthesis of 2-aminochromene 27 in 90\% yield (Scheme 10) [23] The synthesis proceeds through a cascade reaction of salicylaldehyde (5) and malononitrile (20) involving an aldol reaction followed by intramolecular cyclization and finally a dehydration to give intermediate 21. A subsequent Michael addition of the indole (25) to intermediate $\mathbf{2 1}$ gives cation $\mathbf{2 6}$, which loses a proton to give the product 27. Although Shanti and co-workers used a chiral catalyst, no data was provided on the stereoselectivity of this reaction.

In a study related to that of Shanti and co-workers, Yang and co-workers used chiral amine-thiourea catalyst $\mathbf{3 1}$ in a three- component enantioselective reaction of salicylaldehyde (5), acetonitrile (28) and nitromethane (30) to give 2 -aminochromene 32 in $88 \%$ yield and $84 \%$ enatiomeric excess (Scheme 11) [24]. The reaction was found to be equally efficient when malononitrile (20) and cyanoacetate 29 were used instead of 28. The reaction is thought to proceed through a cascade reaction between salicylaldehyde (5) and acetonitrile (28) involving an aldol reaction, cyclization and dehydration. A subsequent Michael addition of nitromethane (30) to the product of the cascade reaction gave the desired product $\mathbf{3 2}$.

Kovalenko and co-workers used a quantitative amount of piperidine in the reaction of malononitrile derivative $\mathbf{3 5}$ as an enolate equivalent and salicylaldehydes 5 to give 2-iminochromenes 36 in good yields [25]. No Michael addition

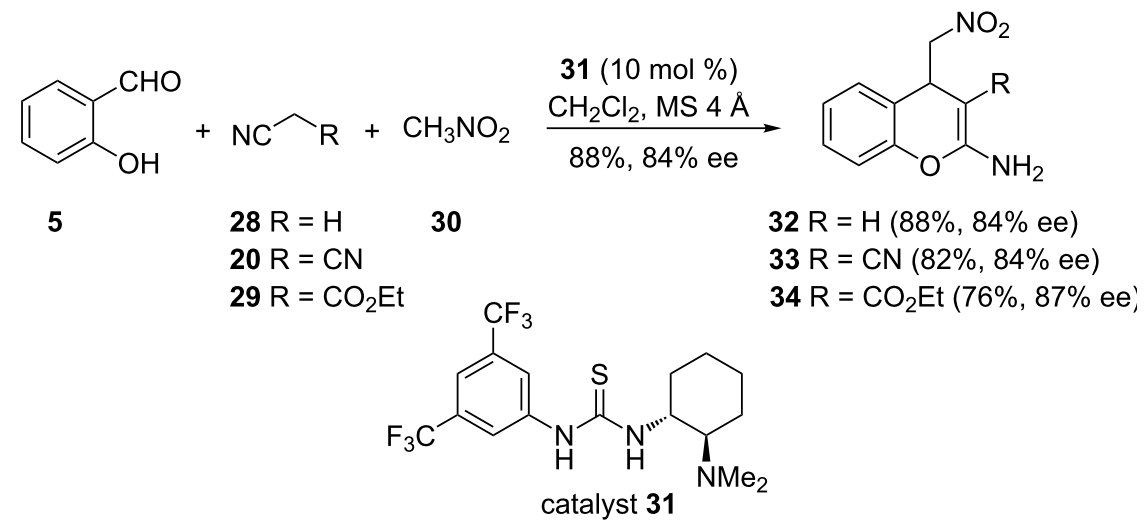




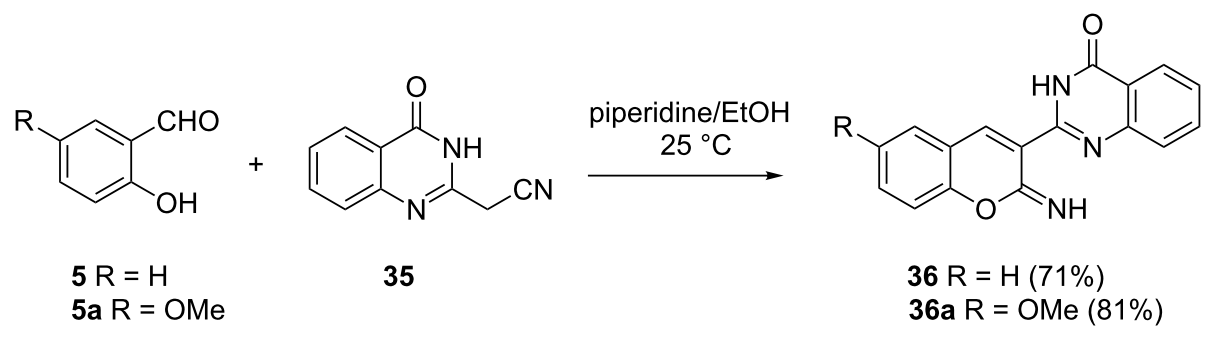

Scheme 12: Synthesis of 2-iminochromene derivatives of type 36 by Kovalenko and co-workers.

product was observed. 2-hydroxy-5-methoxybenzaldehyde (5a) gave product 36a in a higher yield of $81 \%$ compared to salicylaldehyde (5), which gave the corresponding product $\mathbf{3 6}$ in $71 \%$ yield (Scheme 12).

In another approach, Ghorbani-Vaghei and co-workers used a $N, N, N^{\prime}, N^{\prime}$-tetrabromobenzene-1,3-disulfonamide (TBBDA) mediated Knoevenagel reaction of salicylaldehyde (5) and two equivalents of malononitrile (20) or its derivative $\mathbf{2 9}$ to give the corresponding 2-aminochromene derivatives 22 and $\mathbf{3 7}$ in 92 and $82 \%$ yields respectively (Scheme 13) [26]. It is instructive to note that TBBDA is a versatile reagent in organic synthesis and has been reported to be efficient in oxidation of primary and secondary alcohols [27], in bromination of aromatic compounds [28], as catalytic reagents for silylation of alcohols, phenols, and thiols using hexamethyldisilazane [29], in conversion of urazoles to triazolinediones [30], and in oxidation of 1,3,5-trisubstituted pyrazolines [31].

$$
\begin{array}{ll}
5 \quad & \begin{array}{l}
20 \mathrm{R}=\mathrm{CN} \\
29 \mathrm{R}=\mathrm{CO}_{2} \mathrm{Et}
\end{array}
\end{array}
$$

Scheme 13: Synthesis of 2-aminochromenes 22 and 37 by GhorbaniVaghei and co-workers.
Molecular sieves have been used as solid-phase catalysts in the preparation of 2-aminochromenes from salicylaldehyde derivatives and cyanoorganic compounds. Yu and co-workers reported the one-pot synthesis of 2-aminochromene 39 in $86 \%$ yield from the reaction of bromosalicylaldehyde 38 and cyanoacetate $\mathbf{2 9}$ in the presence of $3 \AA$ molecular sieves (Scheme 14) [32]. Various derivatives of $\mathbf{3 9}$ were prepared in good yields by employing nitro-, methoxy-, and chloro-substituted salicylaldehydes instead of 38. Other solid catalysts such as $4 \AA$ molecular sieves, $5 \AA$ molecular sieves and $\mathrm{Al}_{2} \mathrm{O}_{3}$ were found to be effective in catalyzing the reaction but resulted in lower yields (50-63\%) of product 39 [32].

Heravi and co-workers, on the other hand, used a mesoporous molecular sieves (MCM-41)-catalyzed Knoevenagel reaction of salicylaldehyde (5) and malononitrile (20) to give 2-iminochromene 21 in 94\% yield (Scheme 15) [33]. The generality of Haravi's method was demonstrated by the reactions of 3-hydroxy-, 4-hydroxy-, 5-hydroxy-, 4-methoxy- and 5-bromosalicylaldehyde with malononitrile (20) to give the

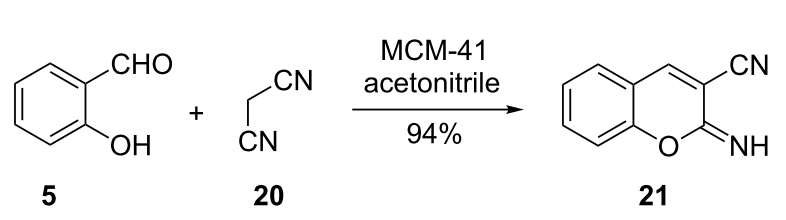

Scheme 15: Synthesis of 2-iminochromene 21 by Heravi and co-workers.

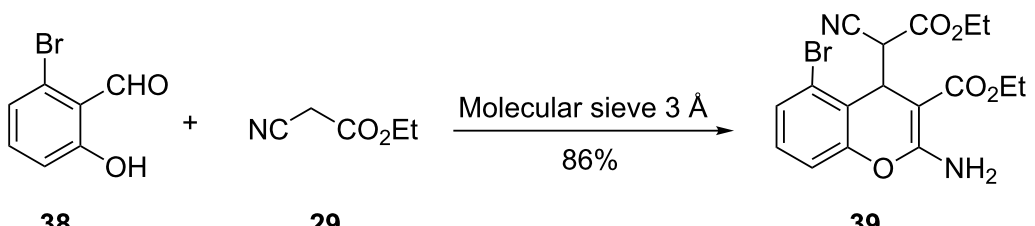




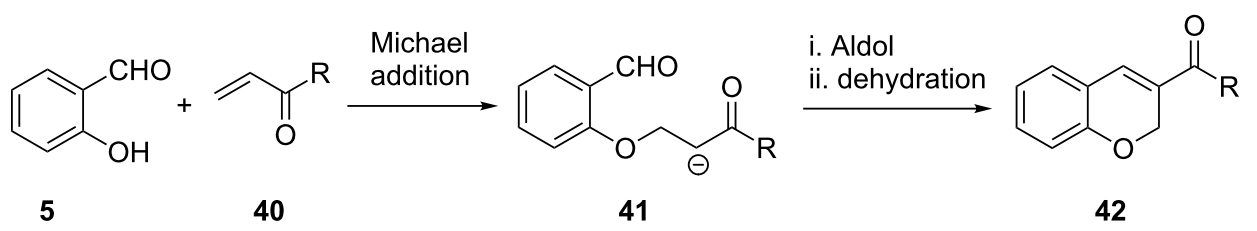

Scheme 16: Tandem reaction of salicylaldehyde and $\alpha, \beta$-unsaturated compounds.

corresponding 2-iminochromene derivatives in yields of at least $90 \%$. MCM-41 can be reused for up to five cycles with an insignificant drop in percentage yields $(80 \%)$.

At this juncture, it is instructive to draw attention to the fact that the yields of the molecular-sieve-catalyzed reactions of salicylaldehydes and enolate equivalents derived from malononitrile and its derivatives are comparable to those of reactions mediated by inorganic bases such as $\mathrm{Na}_{2} \mathrm{CO}_{3}$ (Scheme 7) and $\mathrm{NaHCO}_{3}$ (Scheme 8). However molecular sieves have the advantage that they are recyclable.

\section{Chromane derivatives from the reaction of salicylaldehyde and enolates derived from $\alpha, \beta$-unsaturated compounds}

The tandem reaction of salicylaldehyde and $\alpha, \beta$-unsaturated compounds has proved to be a reliable route to chromane derivatives. In general, this reaction involves an oxo-Michael addition of salicylaldehyde (5) to $\alpha, \beta$-unsaturated compounds of type $\mathbf{4 0}$ to give enolate intermediates of type $\mathbf{4 1}$. Enolate intermediates $\mathbf{4 1}$ then undergo an intramolecular Knoevenagel condensation to give chromane derivatives 42 (Scheme 16).

Kawase and co-workers reported the $\mathrm{K}_{2} \mathrm{CO}_{3}$-mediated tandem reaction of salicylaldehyde derivatives of type 43 and $\alpha, \beta$-unsaturated ester $\mathbf{4 4}$ in the synthesis of 2,2-dimethylchromene $\mathbf{4 5}$ in moderate yields (Scheme 17) [34]. The dehydration reaction in this case was accompanied by decarboxylation. The best yields were achieved when methoxy-, methyl-, chloro-, bromo- and phenyl-substituted salicylaldehydes were used as reagents. The nitro-, hydroxy-, ethoxy- and acetyl-substituted salicylaldehydes on the other hand gave poor yields or no products at all. Related reactions involving a $\mathrm{K}_{2} \mathrm{CO}_{3}$-mediated tandem reaction of salicylaldehyde with acrolein and alkenes with two electron withdrawing groups to give the corresponding chromane derivatives have been reported [35-37]. The percentage yields of the chromane derivatives in these reports were comparable to those reported by Kawase and co-workers.

In addition to $\mathrm{K}_{2} \mathrm{CO}_{3}$, tertiary-amine-mediated tandem reactions of salicylaldehyde and $\alpha, \beta$-unsaturated compounds to give chromane derivatives have been reported. Stukan and co-workers, for example, used an $\mathrm{Et}_{3} \mathrm{~N}$-mediated reaction of salicylaldehyde (5) and nitropropene 46 in the synthesis of 2,3disubstituted chromene 47 in a low yield of $28 \%$ (Scheme 18) [38]. Slightly better yields (33-40\%) were achieved when 5-bromo-, 5-chloro- and 3,5-dichloro-substituted salicylaldehydes were employed in the reaction.

Ravichandran utilized a classical 1,4-diazabicyclo[2.2.2]octane (DABCO)-catalyzed Baylis-Hillman reaction of salicylaldehyde (5) and $\alpha, \beta$-unsaturated compounds 48-51 in the syn-<smiles>CCOC(=O)C=C(C)C</smiles>

43
44

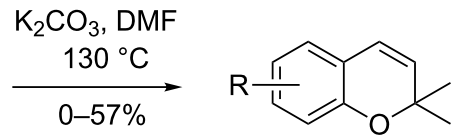

45

Scheme 17: Kawase and co-workers synthesis of 2,2-dimethylchromene 45.<smiles>O=Cc1ccccc1O</smiles>

5<smiles>O=[N+]([O-])/C(Br)=C/C(Cl)(Cl)Cl</smiles>

46

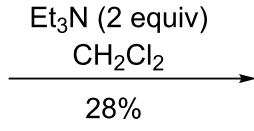<smiles>O=[N+]([O-])C1=Cc2ccccc2OC1C(Cl)(Cl)Cl</smiles>

47 
thesis of the corresponding chromenes 52-55 (Scheme 19) [39]. These reactions were performed in water as the solvent and the chromenes were isolated in yields of $71-79 \%$. It is instructive to note that the Baylis-Hillman products were not detected or isolated in this work.

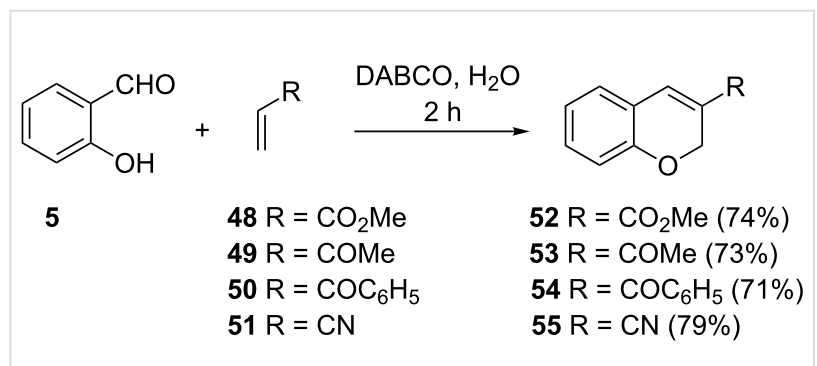

Scheme 19: Ravichandrans synthesis of 3-substituted chromenes 52-55.

The mechanism of the DABCO-catalyzed reaction of salicylaldehyde and $\alpha, \beta$-unsaturated compounds in the synthesis 3 -substituted chromenes was proved to proceed through the Baylis-Hillman reaction by Kaye and co-workers [40,41] Their work involved the reaction of salicylaldehyde (5) with tert-butyl acrylate (56) to give the Baylis-Hillman product 57, which was subsequently cyclized in the presence of acetic acid to give chromene 58 in a low yield of 24\%, together with coumarin 59 in $40 \%$ yield (Scheme 20 ).

An asymmetric amine-catalyzed reaction of salicylaldehyde (5) and $\alpha, \beta$-unsaturated aldehyde $\mathbf{6 0}$ in the synthesis of 2-phenylchromene (62) was reported by Govender and co-workers [42]. The asymmetric union of salicylaldehyde (5) and aldehyde $\mathbf{6 0}$ was brought about by dissolving these two substances in $\mathrm{CH}_{2} \mathrm{Cl}_{2}$ in the presence of catalytic amounts of TMS-protected prolinol derivative 61 (Scheme 21). Methoxysalicylaldehyde 5a reacted much faster than salicylaldehyde (5) with higher isolated yield of 2-phenychromene 63 but at the expense of enantioselectivity. The best enantioselectivity $(90 \%$ ee) was achieved when the aliphatic aldehyde 2-hexenal was used in the reaction instead of $\mathbf{6 0}$. However, the reaction suffered from very poor yields (15-21\%). The reaction is thought to proceed through the condensation of aldehyde $\mathbf{6 0}$ and prolinol 61 to give a chiral iminium-ion intermediate. This intermediate then undergoes a domino reaction involving a Michael reaction with salicylaldehyde (5), followed by an intramolecular aldol reaction and final dehydration to give the desired chromene derivative.

Related work involving asymmetric reaction of salicylaldehyde derivatives and $\alpha, \beta$-unsaturated carbonyl compounds in the syn-<smiles>CC(C)(C)OC(=O)C=CC(=O)OC(C)(C)C1=Cc2ccccc2OC1</smiles>

Scheme 20: Synthesis of 3-substituted chromene 58 coumarin 59 by Paye and co-workers.

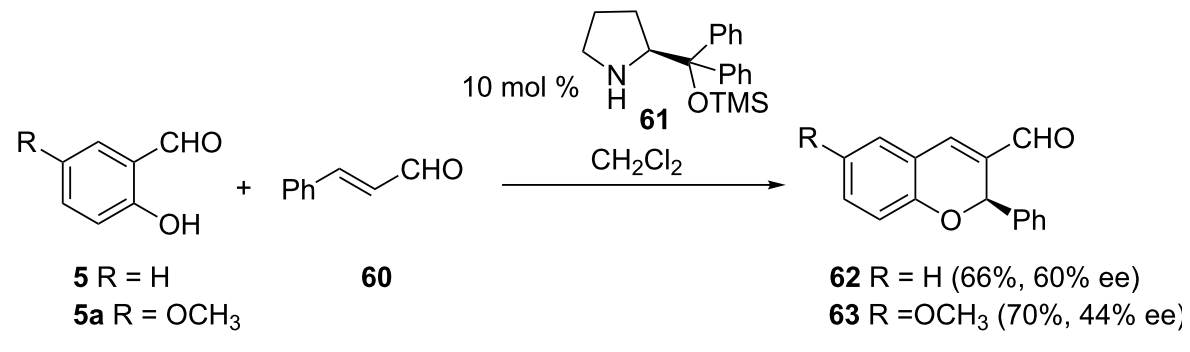

Scheme 21: Govender and co-workers asymmetric synthesis of 2-phenylchromenes 62 and 63. 


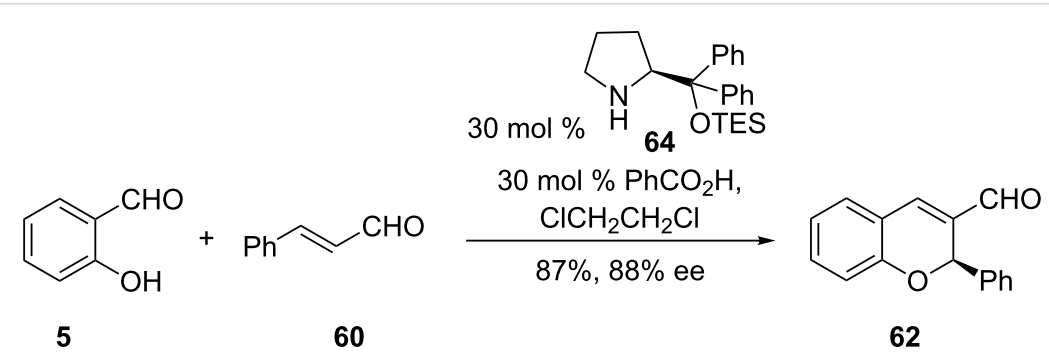

Scheme 22: Asymmetric synthesis of 2-phenylchromene 62 by Li and co-workers.

thesis of 2-phenylchromenes was reported by Li and co-workers (Scheme 22) [43]. Their strategy involved the reaction of salicylaldehyde (5) and unsaturated aldehyde $\mathbf{6 0}$ in the presence of catalytic amounts of TES-protected prolinol $\mathbf{6 4}$ and benzoic acid. High yields (87\%) and excellent enantioselectivity (88\%) of 2-phenylchromene $\mathbf{6 2}$ were achieved when the reaction was performed in 1,2-dichloroethane as the solvent. The presence of the benzoic acid additive is thought to be responsible for the increase in the enantioselectivity and higher yields of this reaction when compared to that of Govender and co-workers. It is also instructive to note that the catalyst loading for $\mathrm{Li}$ and co-workers was three times higher than that for Govender and co-workers.

\section{Conclusion}

This paper has demonstrated the versatility of the reactions of salicylaldehyde with enolates or their equivalents in the synthesis of chromane derivatives. These reactions can be run under quite mild conditions and are ideal for the synthesis of chromane derivatives due to their operational simplicity. The development of enantioselective reactions of salicylaldehyde and enolates to give nearly optically pure chromane derivatives is a memorable highlight of this review. Future work will undoubtedly focus on transformation of the products of the discussed reactions of salicylaldehyde with enolates to biologically active compounds and natural products.

\section{Acknowledgements}

We thank DAAD-NAPRECA for the scholarship (ZYD), the University of Botswana and the Royal Society of Chemistry for financial support.

\section{References}

1. Chang, S.; Grubbs, R. H. J. Org. Chem. 1998, 63, 864-866. doi:10.1021/jo9712198

2. Gowrisankar, S.; Lee, K.-Y.; Kim, J.-N. Bull. Korean Chem. Soc. 2007, 28, 624-628. doi:10.5012/bkcs.2007.28.4.624

3. Ibrahim, M. A.; Ali, T. E.; Alnamer, Y. A.; Gabr, Y. A. ARKIVOC 2010, (i), 98-135.

4. Khadem, S.; Marles, R. J. Molecules 2012, 17, 191-206. doi:10.3390/molecules 17010191
5. Patil, R. B.; Sawant, S. D.; Thombare, P. A. Int. J. Pharm. Tech. Res. 2012, 4, 375-381.

6. Corradini, E.; Foglia, P.; Giansanti, P.; Gubbiotti, R.; Samperi, R.; Laganà, A. Nat. Prod. Res. 2011, 25, 469-495. doi:10.1080/14786419.2010.482054

7. Verma, A. K.; Pratap, R. Tetrahedron 2012, 68, 8523-8538. doi:10.1016/j.tet.2012.06.097

8. Cha, J.-H.; Cho, Y.-S.; Koh, H.-Y.; Lee, E.; Kim, Y.-T.; Yang, H.-H.; Kang, H.-Y. Bull. Korean Chem. Soc. 2004, 25, 1123-1124. doi:10.5012/bkcs.2004.25.8.1123

9. Lee, J.-I.; Son, H.-S.; Jung, M.-G. Bull. Korean Chem. Soc. 2005, 26, 1461-1463. doi:10.5012/bkcs.2005.26.9.1461

10. Miyazaki, H.; Honda, Y.; Honda, K.; Inoue, S. Tetrahedron Lett. 2000, 41, 2643-2647. doi:10.1016/S0040-4039(00)00236-7

11. Petasis, N. A.; Butkevich, A. J. Organomet. Chem. 2009, 694, 1747-1753. doi:10.1016/j.jorganchem.2008.11.050

12. Rodriguez, I.; Iborra, S.; Rey, F.; Corma, A. Appl. Catal., A: Gen. 2000, 194-195, 241-252. doi:10.1016/S0926-860X(99)00371-3

13. Shi, Y.; Shi, M. Org. Biomol. Chem. 2007, 5, 1499-1504. doi:10.1039/b618984a

14. Wang, Q.; Finn, M. G. Org. Lett. 2000, 2, 4063-4065. doi:10.1021/ol006710r

15. Yadav, J. S.; Reddy, B. V. S.; Chandraiah, L.; Jagannadh, B.; Kumar, S. K.; Kunwar, A. C. Tetrahedron Lett. 2002, 43, 4527-4530. doi:10.1016/S0040-4039(02)00816-X

16. Yadav, J. S.; Reddy, B. V. S.; Parisse, C.; Carvalho, P.; Rao, T. P. Tetrahedron Lett. 2002, 43, 2999-3002. doi:10.1016/S0040-4039(02)00440-9

17. Yadav, J. S.; Reddy, B. V. S.; Aruna, M.; Venugopal, C.; Ramalingam, T.; Kumar, S. K.; Kunwar, A. C. J. Chem. Soc., Perkin Trans. 1 2002, 165-171. doi:10.1039/B109538M 18. Xue, J. J.; Zhang, X. S.; Liang, X. Z.; Li, Y. Chin. Chem. Lett. 2003, 14, 443-444.

19. Mazimba, O.; Masesane, I. B.; Majinda, R. R. Tetrahedron Lett. 2011, 51, 6716-6718. doi:10.1016/j.tetlet.2011.09.147

20. Sashidhara, K. V.; Kumar, M.; Kumar, A. Tetrahedron Lett. 2012, 53, 2355-2359. doi:10.1016/j.tetlet.2012.02.108

21. Li, Y.; Chen, H.; Zeng, Z.; Wang, X.; Shi, D.; Tu, S. Chin. J. Org. Chem. 2005, 25, 846-849.

22. Costa, M.; Areias, F.; Abrunhosa, L.; Venancio, A.; Proenca, F. J. Org. Chem. 2008, 73, 1954-1962. doi:10.1021/jo702552f

23. Shanthi, G.; Perumal, P. T.; Rao, U.; Sehgal, P. K. Indian J. Chem. 2009, 48B, 1319-1323.

24. Yang, G.; Luo, C.; Mu, X.; Wang, T.; Liu, X.-Y. Chem. Commun. 2012, 48, 5880-5882. doi:10.1039/c2cc30731f

25. Kovalenko, S. M.; Bylov, I. E.; Sytnik, K. M.; Chernykh, V. P.; Bilokin, Y. V. Molecules 2000, 5, 1146-1165. doi:10.3390/51001146 
26. Ghorbani-Vaghei, R.; Toghraei-Semiromi, Z.; Karimi-Nami, R. J. Braz. Chem. Soc. 2011, 22, 905-909.

27. Ghorbani-Vaghei, R.; Veisi, H.; Amiri, M. J. Chin. Chem. Soc. 2007, 54, 1257-1260.

28. Ghorbani-Vaghei, R.; Jalili, H. Synthesis 2005, 1099-1102. doi:10.1055/s-2005-861851

29. Ghorbani-Vaghei, R.; Zolfigol, M.; Chegeny, M.; Veisi, H. Tetrahedron Lett. 2006, 47, 4505-4508. doi:10.1016/j.tetlet.2006.03.157

30. Zolfigol, M. A.; Ghorbani-Vaghei, R.; Mallakpour, S.; Chehardoli, G.; Choghamarani, A. G.; Yazdi, A. H. Synthesis 2006, 1631-1634. doi:10.1055/s-2006-926446

31. Ghorbani-Vaghei, R.; Azarifar, D.; Maleki, B. Bull. Korean Chem. Soc. 2004, 25, 953-954. doi:10.5012/bkcs.2004.25.7.953

32. Yu, N.; Aramini, J. M.; Germann, M. W.; Huang, Z. Tetrahedron Lett. 2000, 41, 6993-6996. doi:10.1016/S0040-4039(00)01195-3

33. Heravi, M. M.; Poormohammad, N.; Yahia, Sh.; Beheshtiha, Y. S.; Baghernejad, B.; Malakooti, R. Bull. Chem. Soc. Ethiop. 2010, 24, 273-276.

34. Kawase, Y.; Yamaguchi, S.; Horita, H.; Taneko, J.; Kameyama, H. Bull. Chem. Soc. Jpn. 1982, 55, 1153-1155. doi:10.1246/bcsj.55.1153

35. Conti, C.; Desideri, N. Bioorg. Med. Chem. 2010, 18, 6480-6488. doi:10.1016/j.bmc.2010.06.103

36. Yamaguchi, S.; Saitoh, T.; Kamiumezawa, M.; Enomoto, H.; Kawase, Y. J. Heterocycl. Chem. 1992, 29, 755-758. doi:10.1002/jhet.5570290412

37. Sharma, K. K.; Krupadanam, G. L. D. Synth. Commun. 2002, 32, 1557-1562. doi:10.1081/SCC-120004146

38. Stukan, E. V.; Makarenko, S. V.; Berestovitskaya, V. M. Russ. J. Gen. Chem. 2011, 81, 155-157. doi:10.1134/S1070363211010294

39. Ravichandran, S. Synth. Commun. 2001, 31, 1233-1235. doi:10.1081/SCC-100104009

40. Kaye, P. T.; Musa, M. A.; Xolani, W.; Nocanda, X. N.; Robinson, R. S. Org. Biomol. Chem. 2003, 1, 1133-1138. doi:10.1039/b300360d

41. Musa, M. A. Applications of the Baylis-Hillman reaction in the synthesis of coumarin derivatives. Ph.D. Thesis, Rhodes University, 2002. http://eprints.ru.ac.za/2319/

42. Govender, T.; Hojabri, L.; Moghaddam, F. M.; Arvidsson, P. I. Tetrahedron: Asymmetry 2006, 17, 1763-1767. doi:10.1016/j.tetasy.2006.06.028

43. Li, H.; Wang, J.; E-Nunu, T.; Zu, L.; Jiang, W.; Wei, S.; Wang, W. Chem. Commun. 2007, 507-509. doi:10.1039/b611502k

\section{License and Terms}

This is an Open Access article under the terms of the Creative Commons Attribution License

(http://creativecommons.org/licenses/by/2.0), which permits unrestricted use, distribution, and reproduction in any medium, provided the original work is properly cited.

The license is subject to the Beilstein Journal of Organic Chemistry terms and conditions:

(http://www.beilstein-journals.org/bjoc)

The definitive version of this article is the electronic one which can be found at:

doi:10.3762/bjoc.8.244 